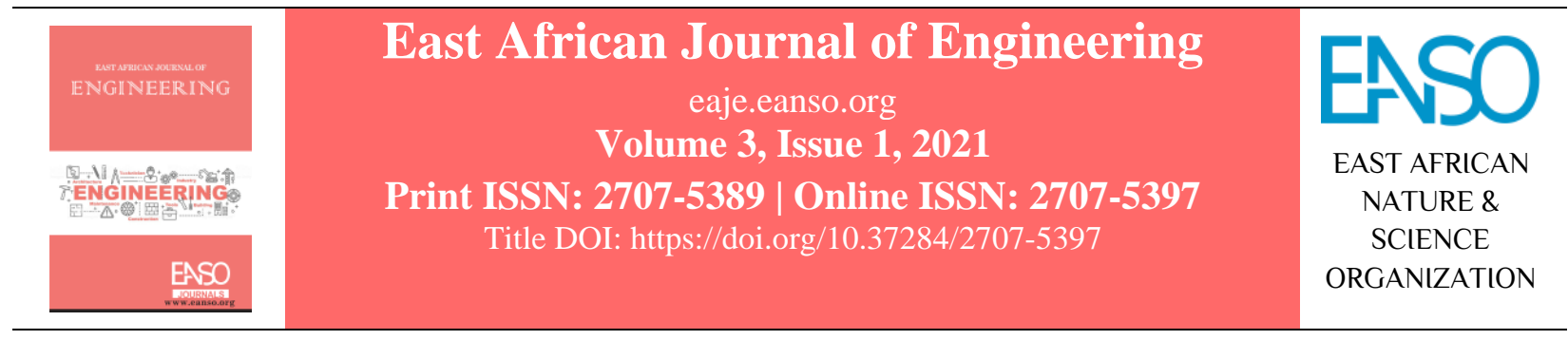

Original Article

\title{
Safety and Compliance in Selected Construction sites of Nairobi County: A case Study of Reynolds Construction Company Nairobi Kenya.
}

\author{
Wilson Kabiru Wanjiru ${ }^{l} \&$ Dr John Ndikaru wa Teresia, $P h D^{l}$ \\ ${ }^{1}$ The Technical University of Kenya, P O Box 52428 - 00200, Nairobi, Kenya. \\ * Author for Correspondence Email: jndikaru@gmail.com.
}

Article DOI: https://doi.org/10.37284/eaje.3.1.388

\section{Publication Date: ABSTRACT}

17 August 2021 Health and safety issues are a critical consideration in workplaces and more particularly, construction sites where accidents are prone to occur. This study

Keywords: aimed at examining the compliance levels of health and safety issues at construction sites in Kenya based on the case of Reynold Construction Company

Safety, in Nairobi County. The study adopted a quantitative research design. Stratified Variables, sampling was adopted and therefore, the target research population was divided into strata that consisted of departments in the organization, where $5 \%$ of the population were sampled from each department. A total of 45 respondents were selected out of 250 employees at Reynold Construction Company. The Employment, questionnaire, observation method and document analysis were used to collect salary, data. Descriptive analysis was used for the quantitative data that was collected Health, using the questionnaire. The study found that safety is addressed to some extent Construction, at the company but there is still room for improvement especially on health Accident, preparedness. The study concluded that the company's employees should be Preparedness. shown safety audit documents that addresses all areas of safety and health. The employees should be involved in workplace inspection. A health and safety committee should be inclusive of all cadres.

\section{APA CITATION}

Wanjiru, W. K., \& wa Teresia, J. N. (2021). Safety and Compliance in Selected Construction sites of Nairobi County: A case Study of Reynolds Construction Company Nairobi Kenya. East African Journal of Engineering, 3(1), 50-56. https://doi.org/10.37284/eaje.3.1.388

\section{CHICAGO CITATION}

Wanjiru, Wilson Kabiru, \& John Ndikaru wa Teresia. 2021. "Safety and Compliance in Selected Construction sites of Nairobi County: A case Study of Reynolds Construction Company Nairobi Kenya”. East African Journal of Engineering 3 (1), $50-56$. https://doi.org/10.37284/eaje.3.1.388.

\section{HARVARD CITATION}

Wanjiru, W. K., and wa Teresia, J. N. (2021) "Safety and Compliance in Selected Construction sites of Nairobi County: A case Study of Reynolds Construction Company Nairobi Kenya", East African Journal of Engineering, 3(1), pp. 50-56. doi: 10.37284/eaje.3.1.388.

50 | This work is licensed under a Creative Commons Attribution 4.0 International License. 


\section{IEEE CITATION}

A. M., Wanjiru., \& wa Teresia, J. N., "Safety and Compliance in Selected Construction sites of Nairobi County: A case Study of Reynolds Construction Company Nairobi Kenya” EAJE, vol. 3, no. 1, pp. 50-56, Aug. 2021.

\section{MLA CITATION}

Wanjiru, Wilson Kabiru, \& John Ndikaru wa Teresia. "Safety and Compliance in Selected Construction sites of Nairobi County: A case Study of Reynolds Construction Company Nairobi Kenya." East African Journal of Engineering, Vol. 3, no. 1, Aug. 2021, pp. 50-56, doi:10.37284/eaje.3.1.388.

\section{INTRODUCTION}

Health and safety issues are a critical consideration in workplaces and more particularly, construction sites where accidents are prone to occur. However, it is not automatic that health and safety issues are prioritized considering the increase in reports about incidents of accidents and fatalities at the workplace and more specifically construction sites. Bermardin (2007) points out that most workplaces have poor occupational health and safety mechanisms, a factor that exposes employees to myriad illnesses and injuries.

In Kenya, the construction sector is a key driving force towards achieving Vision 2030, which is the country's blueprint for social, political and economic development. Construction activities account for a significant portion of bank credit involving about Ksh. 264 billion out of the Ksh. 1.3 trillion loans that are issued by commercial banks (Kenya National Bureau of Statistics, 2013). This study aimed at examining the compliance levels of health and safety issues at construction sites in Kenya based on the case of Reynold Construction Company in Nairobi County.

\section{Problem Statement}

Health and safety issues are amongst the most invaluable assets of an effective working environment for organizations. This is because by upholding the health and safety of the workers, an organization invariably promotes productivity, high motivation, and job satisfaction (WHO, 1994). Employees become the first victims of exposures to health and safety hazards, which could include chemicals, faulty or dangerous tools, machinery or equipment at their workplace.

With the mounting public and social pressure, including the rising consumer expectations, organizations have been prompted to create workplaces that are healthy and secure for their employee, which is beneficial in terms of boosting productivity and competitiveness (Torrington et al., 2008). This, therefore, makes it imperative for investigating the compliance of health and safety issues and challenges in the construction industry, where accidents are highly likely to occur considering the unique nature of this workplace.

\section{EMPIRICAL LITERATURE}

\section{Occupational Health and Safety}

Occupational health and safety can be considered as the physiological-physical and psychological conditions of a workplace that results from the working environment that is provided by the organization. The physiological-physical conductions include occupational accidents and diseases such as loss of limbs or life, while psychological conditions include issues related to mental health such as job burnout (Jackson et al., 2009).

Various gains are associated with upholding health and safety issues at the workplace. According to ILO \& WHO (1995), some of the benefits of observing health and safety at the workplace include achieving a high degree of physical, mental and social wellbeing of the employees. It also reduces employees' turnover as the working environment protects the employees from physical, mental, and social risks that could have driven them to seek employment elsewhere. The organization, therefore, does not have to incur unnecessary expenditures on regular recruitments of new employees.

\section{Occupational Health and Safety Practices}

Most organizations today have adopted practices to improve and maintain employee health and safety at workplace. The effectiveness of health and safety management at the workplace depends upon the nature of the work performance systems and 
organizational work practices as well as the leadership and managerial resilience in seeking continuous improvement of employee health and safety. Armstrong (2006) notes that in the construction industry occupational health and safety practices include all practices, activities, programs and measures undertaken by employers, employees and their organizations as well as designs and architects to protect employee health and promote safety.

Wellness programs are examples of health and safety practices that organizations today are adopting. Torring et al. (2008) point out that an increasing number of employers are establishing stress management programs and physical and health wellness programs to ensure employees retain an essential balance among their life activities. This is expected to serve as a catalyst for enhancing performance and reducing medical expenses incurred.

Other organizations have also adopted health and safety education as a way of equipping their employees with competencies for empowering them to promote the health and safety of themselves and their workplace. Mamoria and Gankar (2011) note that health and safety education aim at building up a favorable attitude towards safety measures and precaution measures while training is concerned with providing the immediate job knowledge, skills, and methods of work, and creating awareness on the hazards likely to be encountered in the course of work. The process also enables understanding the causes of accidents and how they may be prevented importance of good housekeeping and handling of materials safely.

According to Saleemi (2009), safety education and training develop safety consciousness among employees and results in the safe handling of equipment. It ensures safe work performance on the part of the employee by developing skills in the use and operation of equipment. This training needs to be continuous to ensure effectiveness.

\section{Integration of Health and Safety with Project Management}

Current trends regarding health and safety in the construction industry focus on the integration of health and safety management in the whole construction process. All stakeholders are also required to take part in maintaining the health and safety measures that are being practiced in the industry, in all phases of a project (Hinze, 1998).

Various studies have applauded the integration of health and safety practices into construction projects (Kartam 1997; Cameron and Duff, 2002; Murray, Langford \& Fisher, 2002; Saurin et al., 2004; Gibb, 2005; Hare et al., 2006; Pauth et al., 2004). The work of these authors has, each sought to explore avenues for managing health and safety as an integral aspect for project planning during one or more of the phases of project execution.

For instance, Hare et al. (2006) investigated the integration of health and safety with the preconstruction phase of projects. The study highlighted the importance of effective teams and effective two-way communication for successful integration in developing countries. Singh, Hinze and Coble (1999) note that this shift in focus of health and safety management from actual site processes to the overall management of projects requires first of all commitment on part of governments. This creates an enabling environment for the particular clients' designs and health and safety stakeholders in health and safety management.

According to Hawkins (2002), compliance involves applying measures designed to comply with legal requirements to improve outcomes rather than avoid prosecution. Idubor and Osiamoje (2013) noted that the lack of strict enforcement of OSH regulations indicated that non-compliance to $\mathrm{OSH}$ regulations is a major contributor to the poor state of $\mathrm{OSH}$ in Nigeria. Therefore, compliance enhances productivity in industries by reducing accidents, since accidents decrease productivity and increase damage to equipment or property.

Hawkins (2002) discounts the effectiveness of OSH measures in improving health and safety at the workplace. Kamau (2014) argues that the OSH regulations are just symbolic gestures and the prevalence of health and safety abuses on construction sites call for an intensive investigation into the level of health and safety compliance of construction workers. If anything, enforcement and compliance with $\mathrm{OSH}$ regulations are not the 
standalone steps for improving OSH as improving organizational culture can also improve OSH. This also implies that regulations without strict compliance and management commitment amount to a waste of time and resources.

\section{Theoretical Framework}

\section{Distraction Theory}

The study used distraction theory, the proponent of the theory is Hinze (1999) and states that safety is situational because mental distraction varies, the responses to them may have to differ to maintain safe performance. Additionally, hazards or physical conditions with inherent qualities that can cause harm may or may not be recognized by the worker and influence the safety of the task. The theory applies to a situation in which recognized safety hazards or mental distractions exist and there is a well-defined work task to perform. In the absence of hazards there is little to prevent workers from completing their tasks, however, in the presence of hazards work is greatly complicated.

\section{Herzberg's Two Theory}

This theory attempts to explain job satisfaction and motivation. It states the satisfaction and dissatisfaction are driven by different factors motivation and hygiene factors respectively. According to Herzberg (1966), hygiene factors are those that are related to job context and are environmental in nature they include company policy, supervision, interpersonal relations and working conditions.

\section{Conceptual Framework}

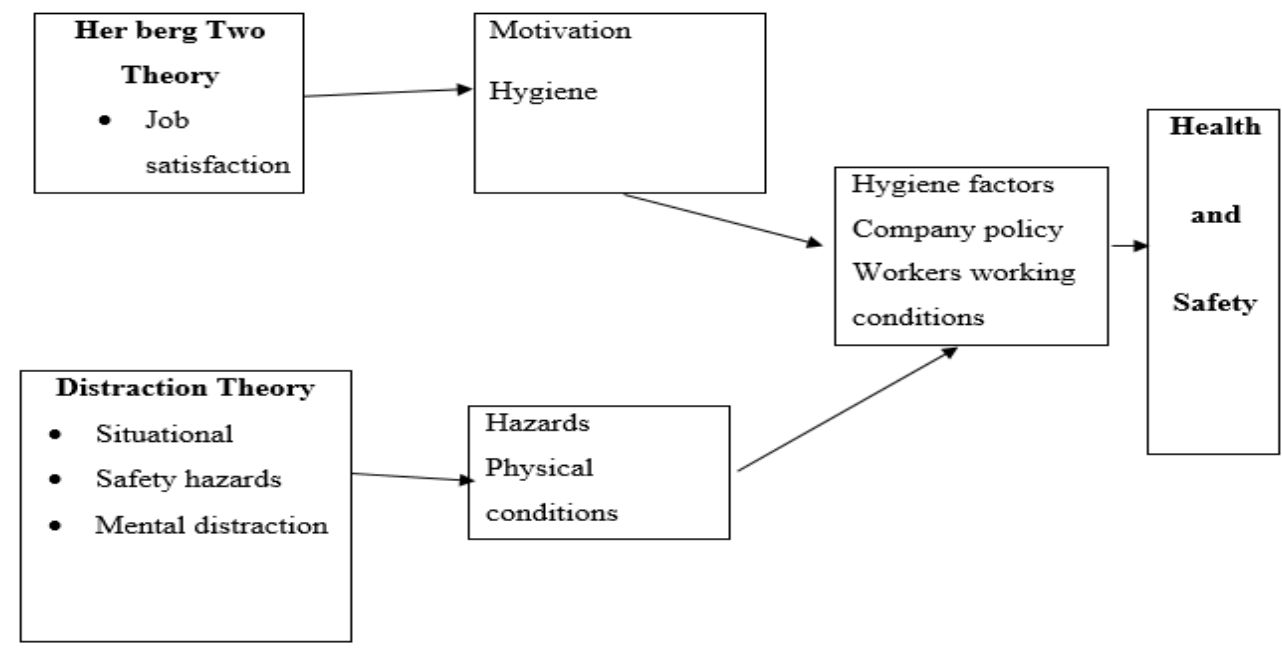

\section{METHODOLOGY}

The study adopted a quantitative research design. Fellows and Liu (2015) notes that a deductive and objective view is characterized by tangible data such as counts, weight, mass and other physical measures. This design is chosen by the researcher because it will allow him to conduct a survey methodology that involves either interviewing or administering questionnaires. Observation will be used in areas of interest under controlled conditions produced by the researcher. The target population consisted of all employees of Reynold Construction Company, permanent and those on contract basis.

The sampling design used both stratified sampling and simple random sampling. The research population was therefore divided into strata that consisted of departments in the organization, where $5 \%$ of the population was sampled from each department. Simple random sampling was therefore used to select those who responded to the questionnaire. 
A total of 45 respondents were selected out of 250 employees at Reynold Construction Company. The three methods used to collect data included the questionnaire, which was distributed to the sampled respondents; the observation method and the analysis of documents. Descriptive analysis was used for the quantitative data that was collected using the questionnaire.

\section{RESULTS AND FINDINGS}

\section{Rate of Response}

The study was conducted at Reynold Construction Company Ltd along Mombasa Road. The researcher collected data relevant to the study distributed fortyfive questionnaires which were issued to the respondents. A total of 38 out of 45 questionnaires were completed and returned, which implied that the response rate of the study was $84 \%$. The response is acceptable and representatives who conform to Mugenda and Mugenda (1999) stipulate that a response rate of $50 \%$ is adequate for analysis and reporting a rate of $60 \%$ is good and a response rate of $70 \%$ and over is excellent.

\section{Demographic Characteristics of Respondents}

The findings indicated that $98 \%$ of the respondents were male while $2 \%$ were female. This demonstrated that the majority of employees in Reynold Construction Company are male. This indicated that the industry is a male-dominated industry due to the hardship and heavy tasks involved.

The findings showed that the majority of the respondents were aged between 20-35 years (65\%). About $15 \%$ were aged between 36 to 45 years; $10 \%$ were aged between 45 to 55 years $(10 \%)$, while $5 \%$ were aged above 55 years. The results of the study revealed that $75 \%$ of the workers were on contract while $25 \%$ were permanent basis. The study found that all the respondents $(100 \%)$ were being employed by the main contractor. This shows that there are no sub-contractors or other specified employers. The study found that the respondents were working in management and supervisory roles and other cadres. This implies that the information collected was well represented at all levels of the company were on contract while $25 \%$ were permanent basis. The study found that all the respondents $(100 \%)$ were being employed by the main contractor. This shows that there are no subcontractors or other specified employers. The study found that the respondents were working in management and supervisory roles and other cadres. This implies that the information collected was well represented at all levels of the company.

\section{Knowledge of Health Safety}

The study found out that the respondents have knowledge of health and safety, however, they lack knowledge of health and safety policy and also the study revealed that there is no safety and health committee.

\section{Table 1: Knowledge on Health Safety}

\begin{tabular}{ll}
\hline Knowledge of health and safety & Percentage \\
\hline Safety and Health awareness in the workplace & $90 \%$ \\
Source of information and Health awareness short training & $90 \%$ \\
Healthy and Safety policy & $5 \%$ \\
Safety and Health committee & $0 \%$ \\
\hline
\end{tabular}

The findings on health prepared measures revealed that the majority of respondents had a positive perception except for safety audits and inspections which were negative. The findings on health preparedness measures revealed that the majority of respondents had a negative perception. This implies there were no health preparedness measures.

\section{CONCLUSION AND RECOMMENDATIONS}

From the findings of the research, it is evident that safety is addressed to some extent but there is still room for improvement especially on health preparedness. Employees should be shown safety audit documents since it addresses all areas on safety and health. The employees should be 
involved in workplace inspection and a health and safety committee should be inclusive of all cadres.

There were a number of limitations that affected the outcome of the study, for instance, data was collected from a sample population from one Construction Company. The findings may therefore not be used to generalize the safety and compliance in all construction companies in Nairobi.

The other limitation was the response rate it was not possible to get all questionnaires returned. For instance, respondents who work in the management feel safe than those in the construction site. Future researchers should investigate other construction industries in other areas in order to establish whether the same results would be replicated.

\section{ACKNOWLEDGEMENTS}

We wish to appreciate the support of the participants in this research.

\section{AUTHORS' CONTRIBUTIONS}

The first and second authors participated in the research process from research conception to the development of research tools, data collection, analysis and writing of the research report.

\section{REFERENCES}

Armstrong, M. (2006). A handbook of human resource management practice. Kogan Page Publishers.

Bermardin, H.J. (2007). Human Resources Management: An Experiential Approach. McGraw Hill Company.

Cameron, I., \& Duff, R. (2002). A report on research into the integration of safety planning and the communication of risk information within existing construction project structures. In Proceedings of Triennial Conference CIB W099 Implementation of Safety and Health on Construction Sites (pp. 1-6).

Fellows, R. F., \& Liu, A. M. (2015). Research methods for construction. John Wiley \& Sons.
Gibb, A. G. F. (2005). Rethinking and revitalising occupational health in construction-A global challenge. In Proceedings of the 4 the Triennial International Conference of the CIB W99 Working Commission (pp. 1-14).

Hare, B., Cameron, I., \& Duff, A. R. (2006). Exploring the integration of health and safety with pre-construction planning. Engineering, construction and architectural management.

Hawkins, K. (2002). Law as last resort: Prosecution decision-making in a regulatory agency. Oxford University Press on Demand.

Herzberg, F. (1966). Work and the nature of man. Cleveland. World, 290, 339-341.

Hinze, J. (2005). Concealing the occurrence of construction injuries. In The W99 Triennial Conference, Rethinking and Revitalizing Construction Safety, Health, Environment and Quality (pp. 714-727).

Idubor, E. E., \& Oisamoje, M. D. (2013). An exploration of health and safety management issues in Nigeria's effort to industrialize. Europ ean Scientific Journal, 9(12).

ILO \& WHO Committee. (1995). Definition of Occupational and Safety. 12th Session of Joint ILO/WHO Committee on Occupational Health. ILO \& WHO Committee

Jackson et al 2009 managing human resource $10^{\text {th }}$ edition occupation health, United States of America Cengage learning

Kamau, E. N. (2014). Enforcement and compliance on occupational health and safety measures in industries in Thika municipality, Kiambu County. Kenyatta University.

Kartam, N. A. (1997). Integrating safety and health performance into construction CPM. Journal of Construction Engineering and Management, 12 3(2), 121-126. 
Kenya National Bureau of Statistics. (2013). Exploring Kenya's inequality: Pulling apart or pooling together. Kenya National Bureau of Statistics and Society for International Development-East Africa

Mamoria, C., \& Gankar, S. (2011). Personnel management. Mumbai: Himalaya Publishing House PVT Ltd.

Mugenda, O. M., \& Mugenda, A. G. (1999). Research methods: Quantitative and qualitative approaches. Acts press.

Murray, M., Langford, D., \& Fisher, S. (2002, September). Dirty construction workers: who you looking at buddy? CIB.

Saurin, T. A., Formoso, C. T., \& Guimarães, L. B. (2004). Safety and production: an integrated planning and control model. Construction Management and Economics, 22(2), 159-169.

Singh, A., Hinze, J., \& Coble, R. J. (Eds.). (1999). Implementation of Safety and health on Construction Sites. CRC Press.

World Health Organization (WHO). (1994). Assessment of fracture risk and its application to screening for postmenopausal osteoporosis: report of a WHO study group [ meeting held in Rome from 22 to 25 June 1992] .World Health Organization. 